\title{
UFRS Uygulanma Sürecinde Hisse Senedi Piyasa Değeri İle Hisse Başına Kazanç ve Hisse Senedi Defter Değeri Arasındaki İlişki (BİST 50’ye Dayalı Bir Uygulama)
}

\author{
The Relationship Between Market Value Per Share, Earnings Per Share \\ and Book Value Per Share in IFRS Implementation Process \\ (Evidence from the BIST 50)
}

\author{
Alper Oflas ${ }^{1} \oplus$, Mohammad Reza Toutounchi Asl ${ }^{1} \odot$ \\ 'Doktora Öğrencisi, İstanbul Üniversitesi, İşletme Fakültesi, Muhasebe Bilim Dalı, İstanbul, Türkiye
}

ORCID: A.O. 0000-0002-9003-4348; M.T.A. 0000-0002-9650-9244

\section{ÖZ}

21. Yüzyılın başından beri finansal raporlamanın en önemli kriteri Uluslararası Finansal Raporlama Standartlarıdır (UFRS). Bu sürecin uygulanması; finansal raporlamanın kalitesini ve karşılaştırılabilirliğini artırarak, hisse senetlerin değerlerini ve ardından yatırımcıların kararlarını etkilemektedir. Bu araştırmanın amacı UFRS'lerin kabul ve uygulanma etkisinin hisse senedinin piyasa fiyatında yarattı̆̆ı değişikliklerin istatistiksel gücünü açılamaktır. $\mathrm{Bu}$ araştırmada hisse senedinin defter değeri ve hisse başına kazanç bağımsız değişken ve hisse senedi fiyatı bağımlı değişken olarak tanımlanmaktadır. Ayrıca istatistik ana kütlesi Borsa İstanbul'da (BİST) işlem gören ve mali olmayan şirketleri kapsamaktadır. Araştırmanın analiz dönemi 19 yıllık (20002018) bir inceleme ve aktif olan BİST 50'deki şirketler örneklem kümesi olarak listelenmektedir. Bu doğrultuda, araştırma verileri yıllık olarak (Kesit Veri) toplanıp analize hazırlanmakta ve tümü için en küçük kareler regresyon yöntemi kullanılmaktadır. Araştırmanın analiz döneminde sonuçlar, muhasebe standartlarının ve finansal raporlama standartlarının onaylanıp yayınlanması ve uygulamaya geçmesi araştırmanın değişkenleri arasındaki ilişkinin artmasını ve regresyonun 2005'ten 2018'e kadar (0.4713) rakamından (0.8740) rakamına doğrudan artmasını göstermektedir.

Anahtar kelimeler: Uluslararası finansal raporlama standardı (UFRS), hisse senedi defter değeri, hisse senedi piyasa değeri, hisse başına kazanç (TMS 33)

\section{ABSTRACT}

Since the beginning of 21st Century, financial reporting has served as the most authoritative criteria of International Financial Reporting Standards (IFRS). The implementation process requires improvement in the quality and comparability of financial reporting and impacts stock value and investors' decisions. The aim of this study is to determine the statistical power of changes in stock market prices due to the adoption and implementation of IFRS. In this study, book value and earnings per share are defined as independent variables and market value per share is the dependent variable. The statistical subjects of the study included all nonfinancial companies that have been traded in Borsa Istanbul. As the sample set, the research presents a 19-year (2000-2018) review of 24 companies in BIST 50, that are active during the study. Accordingly, data are collected annually (cross-sectional data) and a Least Squares Regression method is applied for analysis. The results reveal that the approval, publication, and implementation of accounting and financial reporting standards increase the relationship between the variables of study and regression increases directly from (0.4713) to (0.8740) from 2005 to 2018.

Keywords: International financial reporting standard (IFRS), book value per share, market value per share, earnings per share (IAS 33)

Başvuru/Submitted: 23.12.2019 Revizyon Talebi/Revision Requested: 01.05.2020 Son Revizyon/Last Revision Received: 10.06.2020 Kabul/Accepted: 04.11.2020 Sorumlu yazar/Corresponding author: Mohammad Reza Toutounchi Asl / mohammadreza.toutounchiasl@ogr.iu.edu.tr Atıf/Citation: Oflas, A. ve Toutounchi Asl, M.R. (2021). UFRS uygulanma sürecinde hisse senedi piyasa değeri ile hisse başına kazanç ve hisse senedi defter değeri arasındaki ilişki (BİST 50'ye dayalı bir uygulama). Muhasebe Enstitüsü Dergisi - Journal of Accounting Institute, 64, 71-84. https://doi.org/10.26650/MED.663174 


\section{Extended Abstract}

Regarding stock valuation, the most accepted approach in theory is the "Dividend" approach. Additionally, price/earnings ratio and market value/book value ratio approaches are also used. Book value per share and earnings per share are widely used in stock valuation (Aktaş, 2008). Consequently, when endeavoring to make financial decisions, the information produced in enterprises' accounting information systems must be high quality. With “Qualitative Features of Financial Statements" within the conceptual framework of financial reporting provided by the International Accounting Standards Board, we obtain quality data from the accounting information system. International Financial Reporting Standards (IFRS) make it possible to produce comparable financial statements worldwide. Turkey also adopted these amended and updated international reporting standards. This study examines the effect of the acceptance, publication, and enforcement of IFRS in Turkey on the relationship between market value per share, earnings per share, and stock book value, and whether its intended affects are also applicable in Turkey, based on the results of this analysis.

According to Kaya and Utku's (2019) study on developments in the process of adopting IFRS in Turkey, until 2005 oversight was provided by a Board that was founded in 1994. The aim of this study is to examine the effects of changes to the public reporting of companies' financial performance in transitioning to IFRS in 2005 at 12 different financial rates. The result demonstrates significant differences in long-term financial ratios in Turkey, particularly when the IFRS transition was observed. Çürük and Tanyeri (2018) investigated the impact of the transition to consolidation based on companies traded on the stock market in Turkey. In order to investigate whether the tables issued according to IFRS 10 had any effect on the companies' return, the relationship between the stock return and financial rates was tested using a regression analysis. According to the results, the transition to consolidation is critical, and significant changes have occurred at the level of companies' explanation of return on financial rates following consolidation.

Sultanoğlu (2014) carried out an empirical study on the suitability of financial information presented in the financial statements prepared by businesses traded in Borsa Istanbul in Turkey since 2005 using a panel regression analysis. According to the results, a significant increase in the suitability of financial information to the needs following the implementation of IFRS was demonstrated. Moreover, Return Model analysis results found that an upward change in the net profit value was reflected in the stock return after the transition to IFRS. Şen and Terzi (2013) examined the work of local accounting regulations, International Accounting Standards, and IFRS to investigate the impact of the transition on equity. The analysis determined that the transition to IAS/IFRS had statistically significant effects on the equity items.

Research information is provided via the second source scanning method. To test the research hypothesis, a multivariate regression model is applied using section data. Data were obtained by referring to the financial statements of companies that were accepted and traded in Borsa Istanbul. The financial statements of the selected companies from 2000 to 2018 are analyzed covering 19 years. Analyses of the resulting financial statements are calculated using Microsoft Excel 2016 software. The main subjects of the study are the BIST 50, which was accepted and traded on Borsa Istanbul. Of these 50 companies, 26 were excluded from the analysis for various reasons, leaving a final number of 24 companies included in the research over a 19-year period (456 company-years).

The dependent variable of this study is market value per share and the independent variables are earnings per share and book value per share. Accordingly, a regression model is provided to test the research hypothesis. In this model, the multivariate regression (Multiple R) measures the relationship between variables, the coefficient $\left(\mathrm{R}^{2}\right)$ and the adjusted coefficient determination (Adj. $\mathrm{R}^{2}$ ) measure the power of the independent variables in explaining the dependent variable.

The approval and publication of accounting standards and financial reporting standards within the timeframe of the study were examined and their application was revealed to be correlated with an increase in the relationship between the variables of the research. According to the multivariate regression graph of statistical data resulting from the analysis, there were three peaks: in 2007 (0.5912), 2012 (0.8414), and 2018 (0.8740). The main sources for these three peaks are TFRS 7 with TFRS 7 for 2007; TFRS 10 for 2012; and TFRS 12, TMS 27, TMS 28, TFRS 9, TFRS 15, and TFRS 16 come into force in 
2018. Coefficient and adjusted coefficient of determination increased directly from 2005 to 2018 (0.4713-0.8740). This result can be attributed to the establishment of Turkey's Public Oversight Accounting and Auditing Standards Authority, which provided a valuable focus for investors resulting from the availability of high-quality reports.

IFRS are approved, published, and implemented step-by-step; in other words, standards' implementation of the companies in countries trading on the stock exchange results in improving the quality of financial statements. For this reason, the research results support other studies that have been done before (Wulandari and Rahman, 2004; Callao, 2007; Clarksonve ark., 2011; Çürük and Tanyeri, 2018; Key and Kim, 2020; Kandimov, 2020). 


\section{Giriş}

Hisse senedi, ortaklık sermayesinin belirli bir kısmını temsil eden, sahibine kardan pay alma, rüçhan hakkını kullanma, yönetimi seçme ve yönetime seçilme hakkı yanında tasfiye durumunda tasfiyeden pay alma hakkını veren, değişken gelirli bir menkul değerdir. Seçilecek veya yatırım yapılacak hisse senetlerinin belirlenmesinde, değerleme yöntemleri ve şirketlerin tahmini değerleri kullanılarak, hisse senetlerinin gerçek değerleri hesaplanır. Hesaplanan bu tahmini gerçek değer ile hisse senedinin piyasa fiyatı ile karşılaştırılarak hisse senedinin seçilip seçilmemesine karar verilir. Hisse senedi değerlemesiyle ilgili olarak teoride en çok kabul gören yaklaşım 'kâr Payı" yaklaşımıdır. Bunun yanında Fiyat/Kazanç oranı ve Piyasa Değeri/Defter Değeri oranı yaklaşımları da kullanılan diğer yaklaşımlardır. Hisse senedinin defter değeri ve hisse başına kazanç hisse senedi değerlemesinde yaygın olarak kullanılmaktadır (Aktaş, 2008). Ancak finansal kararların alınmasında, işletmelerin muhasebe bilgi sistemlerinde üretilen bilgilerin kaliteli olması gerekir. Kaliteli bilgiyi tanımlayabilmek için, bilginin tanımını ve niteliksel (kalite) özelliklerini bilmek gerekir. Bilgi, verilerin kullanılabilir hale getirilmesidir. Bilginin niteliksel özelliklerini de; doğruluk, ilgililik, tamlık, zamanlılık, ulaşılabilirlik, anlaşılabilirlik, güvenilirlik, etkin maliyet şeklinde sayabiliriz (Çukacı, 2005). Uluslararası Muhasebe Standartları Kurulu (IASB) tarafından sunulan Finansal Raporlamaya İlişkin Kavramsal Çerçevedeki 'Finansal Tabloların Niteliksel Özellikleri" ile muhasebe bilgi sisteminden kaliteli veriler elde edilebilecektir.

Uluslararası muhasebe standartlarının öneminin artması, uluslararası muhasebe standartlarının kabulünün etkisi hakkında birçok ülkede araştırmaların yapılmasına yol açmıştır. Uluslararası finansal raporlama standartları, uluslararası muhasebe standartlar kurulu (International Accounting Standards Board-IASB) tarafından hazırlanıp sunulmuş bir muhasebe standartlar setidir ki muhasebe ve finansal raporlama uygulamalarını koordine etmek amacıyla tüm dünyada karşılaştırılabilir ortamın oluşturulmasına çalışmaktadır. Uluslararası Muhasebe Standartları taraftarlarına göre bu standartların kabulü uluslararası finansal piyasalarda küresel ticaretin ve sermaye oluşumunun önündeki engelleri ortadan kaldırmaktadır. Bu doğrultuda, küreselleşme eğilimini ve uluslararası finansal piyasaların entegrasyonunu dikkate alarak, her ülke finansal raporlama standartları setini uygulamaya çalışmaktadır. Dolayısıyla Türkiye de gelişmekte olan bir ülke olarak ve ayrıca komşu ülkelerle, özellikle Avrupa Birliği’ne üye olan ülkeler ile iletişim halinde olan bir ülke olarak bu standartları kabul etmekte ve uluslararası finansal raporlara uymak için standartlarını düzeltip güncellemektedir.

Uluslararası Finansal Raporlama Standartlarının (UFRS) kabul edilmesi finansal raporlamanın diğer alanlarını özellikle yatırımcıların kararlarını da etkilemektedir. Bunun için, UFRS’nin uygulanması ile muhasebe bilgi sisteminden daha kaliteli veriler elde edilecek. Elde edilen bu verilerden de hisse senetlerinin değerlemesi daha başarılı olacaktır. Bu doğrultuda yaptığımız araştırmanın mevcut ilişkileri istatistiksel açıdan muhasebe bilgileri ile hisse senedi fiyatları arasındaki ilişikliyi ölçmeye çalışmaktadır. Dolayısıyla bu araştırma Türkiye'de Uluslararası Finansal Raporlama Standartlarının kabulü, yayınlanması ve yürürlüğe girmesinin hisse senedi piyasa değeri ile hisse başına kazanç ve hisse senedi defter değeri arasındaki ilişkiyi etkileyip etkilemediğini ve bu sonuçların Türkiye'de de uygulanabilir olup olmadığını amaçlanmaktadır.

\section{Türkiye'de UFRS'nin Benimsenmesi}

Uluslararası muhasebe standartlarını Türk diline çeviren ve yayımlayan ilk kuruluş Türkiye Muhasebe Uzmanları Derneği (TMUD)'dir. TMUD'de International Accounting Standard Committee (IASC)'ne 1973 yılında üye olmuştur (Karapınar, 2000).

2002'de alınan bir karar ile Avrupa Birliğine üye ülkelerin menkul kıymet borsalarında işlem gören şirketlerinin, 2005 yılının ocak ayından geçerli olmak üzere mali tablolarını UFRS'ye göre hazırlaması zorunluluğu getirilmiştir. Bu karar ile Avrupalı 8000 büyük şirket mali tablolarını UFRS'ye göre hazırlamak zorunda kalmıştır. Türkiye Muhasebe ve Denetim Standartları Kurulu, kurulduğu 1994 yılından beri IAS/IFRS ile uyumlu standartlar oluşturmaya çalışmaktadır (Aysan, 2008).

Türkiye'de uluslararası finansal raporlama standartlarının ilk olarak uygulanmaya başlaması, 15.11.2003 tarihli Seri: 11, No: 25 'Sermaye Piyasasında Muhasebe Standartlarında Hakkında Tebliğ'’in yayınlanması ile Sermaye Piyasası Kurulunda olmuştur. Bu tebliğin, Avrupa Birliğinin mevzuatı ile tamamen uyumlu olabilmesi için yürürlükten kaldırılıp yerine, Seri: 
11, No: 29 "Sermaye Piyasasında Finansal Raporlamaya İlişkin Esaslar Tebliği” 09.04.2008 tarih ve 26842 sayılı resmî gazetede yayımlayarak yürürlüğe konmuştur. Yeni tebliğ ile 01.01.2008 tarihinden itibaren Avrupa Birliği tarafından kabul edilen haliyle UMS/UFRS'lere denk TMS/TFRS'ler, borsaya kote şirketler, aracı kurumlar, portföy yönetim şirketleri ve bu şirketlerin bağlı ortaklıkları, iştirak ve iş ortaklıkları için uygulanmaya başlanmıştır. Bu gelişme ile Türkiye'deki borsaya kote olan şirketler de dünyadaki borsa şirketleri ile karşılaştırılabilir finansal tablolara sahip olmuşlardır (Sultanoğlu, 2014).

Türkiye ekonomisini önemli ölçüde etkileyen 2001 yılındaki finansal kriz sonrasında, ülkemizde Bankacılık sektörünü düzenlemek ve denetlemek için kurulan Bankacılık Düzenleme ve Denetleme Kurumu (BDDK), bankacılık sektöründeki bankaların yılsonu finansal tablolarının uluslararası muhasebe standartları ile uyumlu olabilmesi için, içeriğinde 18 adet tebliğ barındıran Muhasebe Uygulama Yönetmeliği'ni yayınlamıştır. Fakat BDDK, TMSK'nin kurulması ile yayınlamış olduğu tebliğleri 2006 yılında tebliği yürürlükten kaldırarak, TMSK tarafından yayınlanacak TMS'lerin kullanılması gerektiğini bildirmiştir (İbiş ve Özkan, 2006).

13.01.2011 tarihinde yayımlanan 6102 sayılı Yeni Türk Ticaret Kanunu, uluslararası muhasebe standartlarını ve denetim standartlarını benimsemiştir. Bu standartların Türkiye'de uygulanması için, Kamu Gözetimi Muhasebe ve Denetim Standartları Kurumu (KGK) kurulmuştur. KGK, Uluslararası Muhasebe ve Denetim Standartlarını Türkçeye çevirip güncelleştirerek Türkiye Muhasebe ve Denetim Standartlarını oluşturmaya başlamıştır (Güvemli ve Güvemli, 2015).

Muhasebe ve denetim alanındaki standart oluşturma KGK'nin yetkisindedir. KGK, TMSK tarafından kabul edilmiş TMS'leri aynen benimsemiştir. "Uluslararası Finansal Raporlama Standartları" olarak bilinen IFRS'i ve "Uluslararası Denetim Standartları” olarak bilinen ISA'si Türkçe’ye tercüme ederek Türkiye Finansal Raporlama Standartları (TFRS) ve Türkiye Denetim Standartları (TDS) adlarıyla yayımlamış ve yayımlamaya devam etmektedir (Zencirkıran, 2015).

Kamu Gözetimi Muhasebe ve Denetim Standartları kurumu 2014 yılında almış olduğu bir karar ile KAYİK'lerin (kamu yararını ilgilendiren kuruluşları) TMS/TFRS uygulamasının zorunlu olduğunu belirtmiştir. KAYİK olarak tanımlanan işletmeler SPK, BDDK ve Hazine Müsteşarlığı mevzuatına tabi işletmelerdir. TMS/TFRS uygulamayan işletmelerin ise Muhasebe Sistemi Genel Uygulama Tebliğlerini uygulaması istenmiştir. Bağımsız denetime tabi olup da TMS/TFRS uygulamayan işletmeler için ise, "Büyük ve Orta Boy İşletmeler için Finansal Raporlama Standardı (BOBİ FRS)" KGK tarafından 29 Temmuz 2017 tarihli ve 30138 Sayılı Mükerrer resmi gazetede yayımlanmıştır. BOBİ FRS 01.01.2018 tarihi ve sonrası hesap dönemlerinde büyük ve orta boy işletmeler tarafından uygulanmak üzere yürürlüğe girmiştir (Kaya ve Utku, 2019).

\section{Literatür Taraması}

Key ve Kim (2020), Güney Kore'nin 2011 yılında ulusal muhasebe standartlarının yerine UFRS'yi uygulamaya başlamasından sonraki muhasebe kalitesini araştırmışlar. Muhasebe kalitesini araştırmak için, kazanç yönetimi ile alakalı çeşitli değişkenleri ve cari zararı vekil değişken olarak tanımlamışlardır. Güney Kore'nin UFRS'nin kabul süreci ile ilgili raporları, başarılı ve şeffaf bir uygulama için güçlü bir bağlılık göstermiştir. Sonuçta, UFRS'nin uygulanması sermaye piyasaları ve muhasebe ortamı üzerinde olumlu etkileri olduğu görülmüştür.

Kandimov (2020), Bu araştırmada nicel araştırma tasarımını uygulanmış ve 10 Norveç şirketini incelenmiştir. Veriler NASDAQ'da halka açık şirketlerin yıllık raporlarından ve mali tablolarından toplanmıştır. Çeşitli UFRS standartlarının uygulanmasının finansal oranlar üzerindeki etkisini belirlemek için korelasyon ve regresyon testleri yapılmıştır. Çalışma, UFRS'nin karlılığı olumlu etkilediğini ve daha iyi likidite sonuçlarına yol açtığını tespit etti. Ayrıca, daha iyi ödeme gücü oranlarına ve daha iyi piyasa oranlarına ulaşılmasını sağlamıştır.

Alkan (2019), bu çalışmada Tek Düzen Hesap Planı'na (TDHP) göre düzenlenen finansal tablolar, düzeltme ve sınıflandırma kayıtları yapılarak, Türkiye Muhasebe ve Raporlama Standartlarına (TMS/TFRS) uygun hale getirilmiştir. TMS/TFRS'ye uyumlu finansal tablolara geçişin finansal analize etkisini tespit etmek amacıyla oran analizi yöntemi kullanılarak örnek bir uygulama sunulmuş ve farklılıklar karşılaştırmalı olarak incelenmiştir. Oranların, standart uygulamaları kapsamında yapılan hangi düzeltme kayıtları neticesinde farklılık gösterdiği tespit edilmeye çalışılmıştır. 
Kaya ve Utku (2019), Türkiye'de uluslararası standartlara uyum noktasında, Türkiye Muhasebe ve Denetim Standartları Kurulu (TMUDESK)'nun kurulduğu 1994 yılından günümüze kadar gelen süreçte yaşanan gelişmeler incelenmiştir. Çalışmanın temel amacı ise, 2005 yılındaki UFRS'ye geçişin işletmelerin finansal performanslarında yarattığı değişikliğin etkilerini incelemektir. Bu amaçla Türkiye'deki ve Almanya'daki sanayi endekslerinde bulunan ve verisine ulaşılabilen sanayi işletmelerinin 1995-2014 arası yirmi yıllık süreçteki finansal tabloları analiz edilmiş̧ir. Analiz her iki ülke işletmeleri için, 2005 öncesi ve sonrası 3'er y 11 llk ve 10'ar yıllık analiz dönemlerinde, 12 farklı finansal oran üzerinden gerçekleştirilmiştir. Finansal oranlarda meydana gelen değişimin anlamlı olup olmadığı yapılan t testi ile ölçülmüştür. Sonuç olarak UFRS'ye geçiş ile birlikte Türkiye'de özellikle uzun dönemde finansal oranlar üzerinde anlamlı farklılıklar izlenmiştir. Almanya'da ise gerek geçişin yaşandığ i ilk yıllar gerekse 10 yıllık süreçte UFRS'ye geçiş, birkaç finansal oran dışında anlamlı farklılıklar yaratmamışırı. Bu durum Alman muhasebe sisteminin UFRS'ye geçişten önce de hali hazırda uluslararası standartlara yakın finansal raporlar oluşturduğu şeklinde yorumlanabilir.

Çürük ve Tanyeri (2018), Türkiye'de borsada işlem gören firmaları baz alan bu çalışmada, konsolidasyona geçişin firma getirisi üzerindeki etkisi araştırılmıştır. UFRS 10’a göre düzenlenen konsolide finansal tabloların firma getirisi üzerine herhangi bir etkisinin olup olmadığını araştırmak amacıyla, hisse senedi getirisi ile finansal oranlar arasındaki ilişki literatürde yaygın olarak kullanılan Rasyo Modeli (Bayrakdaroğlu, 2012; Büyükşalvarcı ve Uyar, 2012) esas alınarak analiz edilmiştir. Konsolidasyon öncesi (2000-2003), sonrası (2006-2009) ve bu çalışmanın yapıldığı son dönem (2012-2015) bazında 4'ter yıllık periyotları kapsayan, Borsa İstanbul'da işlem gören firmalardan elde edilen veriler regresyon analizi ile test edilmiş̧ir. Araştırma sonuçları, konsolidasyona geçişin önemli olduğuna ve konsolidasyon sonrası finansal oranların firma getirisini açıklama düzeyinde önemli değişiklikler meydana geldiğine işaret etmektedir.

Acaravcı (2016), Borsa İstanbul'da yerel muhasebe düzenlemelerine ve UFRS'ye uyumlu hazırlanan finansal tablolardan elde edilen finansal oranlar ile hisse senedi getirileri arasındaki ilişkiyi belirlemek ve bu ilişkinin uygulanan muhasebe standartlarına göre farklılaşıp farklılaşmadığını ekonometri olarak araştırmaktadır. Elde edilen sonuca göre, UFRS'ye uyumlu hazırlanan finansal tablolardan elde edilen finansal oranların hisse senedi getirilerini açıklama gücünün arttı̆̆ 1 görülmektedir.

Uyar (2015), Türkiye'de TMS/TFRS uygulamalarının halka açık şirketlerin piyasa değerleri üzerindeki açıklama gücünün yerel mevzuatı ifade eden Muhasebe Uygulamaları Genel Tebliği (MSUGT) ile karşılaştırarak analiz etmektir. Test edilmek istenen hipotez IASB'nin standartların oluşturulmasındaki temel hedefi olan kaliteli, anlaşı1ır, genel kabul görmüş ve küresel muhasebe bilgisinin Türkiye piyasasında oluşup oluşmadığının araştırılmasıdır. 2000-2004 ve 2005-2009 dönemlerinde faaliyet gösteren 225 firmanın finansal verilerinin kullanıldığı çalışmada, araştırma tekniği olarak panel veri analizi tercih edilmiştir. Çalışmada, TMS/TFRS uygulamalarına göre hazırlanan mali tabloların yatırımcılar tarafından daha güvenilir kabul edildiği ve 2005 yılı sonrasında, öncesine göre fiyatlamayı daha yüksek ölçüde açıkladığı sonucuna ulaşı1mıştır.

Sultanoğlu (2014), UFRS’nin Türkiye'de 2005 yılından itibaren Borsa İstanbul'da işlem gören işletmelerin hazırladıkları finansal tablolarda sunulan finansal bilginin ihtiyaca uygunluğu ve finansal tablo analizi üzerindeki etkisi ampirik olarak incelenmiştir. İnceleme, UFRS Öncesi (2000-2004) ve UFRS Sonrası (2005-2010) dönemler arası imalat sanayi sektöründe devamlı olarak işlem gören 26 işletme için gerçekleştirilmiştir. Çalışmada, UFRS'nin, finansal bilginin ihtiyaca uygunluğunda bir artış yaratıp yaratmadığını ölçmek için, Fiyat Modeli (Ohlson, 1995) ve Getiri Modeli (Easton ve Harris, 1991), finansal tablo analizi üzerindeki etkisi için ise Rasyo Modeli kullanılarak panel regresyon analizi gerçekleştirilmiştir. İhtiyaca uygunluk için her iki Model ile yapılan analizler sonucunda, UFRS'den sonra, finansal bilginin ihtiyaca uygunluğunda anlamlı bir artış olduğu görülmüştür. Ayrıca, Fiyat Modeli kullanılarak yapılan analiz sonuçlarında, özkaynak defter değerinin işletmelerin piyasa değerlerini açıklamada etkin olduğu bulunmuştur. Getiri Modeli analiz sonuçlarında ise, net kâr değerindeki değişim değerinin UFRS'ye geçişten sonra hisse senedi getirisine yansıması anlamlı bulunmuştur. UFRS'nin finansal tablo analizi üzerindeki etkisini ölçmek için kullanılan Rasyo Modeli sonuçlarında, UFRS'ye göre hazırlanmamış finansal tablolardan elde edilen finansal oranların, UFRS'ye göre hazırlanmış finansal tablolardan elde edilen finansal oranlara göre işletmelerin hisse senedi getirilerini açıklamada daha çok katkı sağladığı söylenebilir. 
Şen ve Terzi (2013), Bu çalışmanın amacı, yerel muhasebe düzenlemelerinden (MUGT), Uluslararası Muhasebe Standartları ve Uluslararası Finansal Raporlama Standartları (UMS/UFRS)'lere geçişin özkaynak üzerindeki etkilerinin araştırılmasıdır. Bunun için Borsa İstanbul'da (BIST) kayıtlı 144 üretim şirketi analize dahil edilmiştir. Yapılan analiz sonucunda UMS/ UFRS'lere geçişin özkaynak kalemleri üzerinde istatistiksel açıdan önemli etkilerinin olduğu tespit edilmiştir. Elde edilen diğer bulgu ise, özkaynak kalemleri içinde en fazla sermaye yedekleri ile geçmiş yıl kar/zararları kalemleri etkilenmiş olduğudur.

Clarkson ve ark. (2011) Avrupa ve Avustralya'da UFRS'nin benimsenmesinin defter değerlerinin ve özkaynak değerlemesi için kazançlar üzerindeki etkilerini araştırmışılardır. Hem doğrusal hem de doğrusal olmayan fiyatlandırma modelleri kullanılmıştır. 2005 yılında ilk olarak UFRS'yi kabul eden 3488 şirketin, UFRS'nin kabul edilmesinden sonraki verilerde doğrusal yönde artış olduğunu bulmuşlardır.

Gaston ve ark. (2010) UFRS'nin benimsenmesinin ilk kez uygulayanlar tarafından yayınlanan finansal raporlama üzerindeki nicel etkisini incelemiştir. Araştırma, finansal bilgilerin ilişki düzeyinin IFRS kapsamında İspanya GAAP'lerinden daha yüksek olup olmadığını analiz etmektedir. 2004'te Madrid Borsa'sında işlem gören 174 şirket için duyarlılık analizini içeren çok değişkenli analiz kullanılmıştır ve İspanya'da ilk kez UFRS'lerin kabul edilmesinin varlıklar ve borçlar üzerinde daha yüksek değer aldığını ve daha kötü finansal pozisyona neden olduğu sonucuna varmaktadırlar.

Beisland ve Knivsfla (2009), yerel GAAP'ten UFRS'ye raporlama rejimine geçişin yatırımcıların muhasebe bilgilerine cevap verme şeklini değiştirip değiştiremediğini (özellikle defter değerleri ve kazançlar) incelemiştir. 2002 yıllı ile 2006 yıllı arasında Oslo Borsa'sında işlem gören 741 şirketi örneklem listesine dâhil ederek regresyon analizini kullanmışlardır. Araştırma, UFRS'ye geçişten sonra hisse senedi fiyatları ile defter değeri arasındaki ilişkinin arttığı, kazanç yanıtları katsayılarının azaldığı sonucuna varmıştır. Defter değeri ile borsa değeri arasındaki artan ilişki, maddi olmayan duran varlıkların daha fazla tanınmasına ve gerçeğe uygun değer ölçümlerine bağlanmaktadır.

Kadri ve ark. (2009) piyasa değeri defter değeri ile Malezya şirketlerinin kazançları arasındaki ilişkiyi iki farklı finansal raporlama ortamında incelemişilerdir; MASB ve FRS. Malezya Borsa'sından 59 listelenmiş şirket için Ohlson Modelini kullanmıştır. Piyasa değeri ile defter değeri ve kazançlar arasında anlamlı bir ilişki olduğunu göstermiştir. FRS döneminde piyasa değeri ile defter değeri ve kazançlar arasında daha önemli bir ilişki bulunmaktadır. Bu nedenle, kısa dönemde FRS uygulamasının ardından defter değeri ve kazançların ilişki düzeyinin arttığı ve kazanımların FRS döneminde defter değerlerinden daha değerli olduğunu bulmaktadırlar.

Callao ve ark. (2007), yeni standartların İspanya'da finansal raporlamanın karşılaştırılabilirliği ve ilişki düzeyi üzerindeki etkisine odaklanmıştır. İki standart seti arasındaki değerin uygunluğunu karşılaştırmak için İspanyol ve IFRS araştırmacıları parametrik ve parametrik olmayan testler uygulamışlardır. Araştırma süresi 2004 ve 2005 yıllarından oluşmaktadır. Araştırma, aynı ülkede ve aynı zamanda hem UFRS'nin hem de yerel standartlarının uygulanması durumunda olumsuz bir etkisinin olduğunu tespit etmiştirler. UFRS uygulandığında, artan defter değeri ile piyasa değeri arasında bir boşluk bulunmaktadır. Nakit ödeme gücü, Borçluluk oranı ve defter değeri ve piyasa değeri olarak finansal performans değişikliği gelir tablosu ve bilançoda farklılık göstermektedir. UFRS kabul edildiğinde kazançların ve defter değerinin ilişki düzeyi artmaktadır.

Wulandari ve Rahman (2004) muhasebe bilgilerinin hisse senetleri fiyatlarına ne kadar yansıdığını ölçmek için değer ilişsisi kavramını incelemiştir. Ülke düzeyindeki değer ilişkisini firma düzeyindeki verileri kullanarak incelemiştir. Çalışmada, üç düzenleyici ayarlamanın (muhasebe standartlarının kalitesi, kabul edilebilirliği ve uygulanabilirliği) ve genel muhasebe düzenleyici ortamının kazanıın değerine ve özkaynakların defter değerine etkilerini araştırmıştır. 35 farklı ülkenin örnek firmaları için anket analizi ve çok değişkenli testler kullanılmıştır. Sonuç olarak, değer ilişkisi muhasebe kazançları ile muhasebe standartlarının cezai yaptırımını, kabul edilebilirlik ve kalitesini içerir. Birleşik değişkenler ve düzenleyici ortam değer ilişkine sahiptir. Finansal raporlama rejimi ve değer ilişkisi arasındaki ilişki, kanun hukukunda ülkelerde ve gelişmekte olan ekonomilerle birlikte gelişmekte olan piyasalarda pozitif ve yüksektir. 
Bartov ve ark. (2002), ABD GAAP, Alman GAAP ve Uluslararası Muhasebe Standartları (IAS)'nin değeri ile olan ilgisini karşılaştırmıştır. 1998-2000 yılları arası dönemini kapsayan, Alman Menkul Kıymetler Borsa'sında listelenen Alman şirketlerinin örnekleminde regresyon analizini kullanmışlardır. Çalışmaları, ABD GAAP'a dayalı kazancın değeri ile ilgi düzeyinin, Alman GAAP kapsamında elde edilen kazançlardan daha değerli olduğu IAS tabanlı kazançlardan daha yüksek olduğu sonucuna varmıştır.

\section{Araştırma Yöntemi ve Bulguları}

\subsection{Hipotez}

Araştırmanın hipotezi beyan edilen amaçların doğrultusunda belirlenmektedir. Daha acık ve net bir ifade ile beyan edilirse bu araştırmanın hipotezi, Uluslararası Finansal Raporlama Standartları (UFRS) sürecinin kabulü ve uygulanması artıkça hisse senedi piyasa değeri ile hisse başına kazanç ve hisse senedi defter değeri arasındaki ilişkinin artırmasını incelemektir.

\subsection{Amaç}

Daha önce yapılmış tüm araştırmalar incelendiğinde; Hisse senedi piyasa değeri ile hisse başına kazanç ve hisse senedi defter değeri arasındaki ilişki üzerine, Türkiye dışında Pakistan'da Rehana Kouser (2011), UFRS’nin benimsenmesi ve Pakistan'daki etkileri konusunda bir araştırma yapmıştır. Bu araştırmada Karaçi Menkul Kıymetler Borsa’sında (KSE) her yıl analiz yaklaşımı kullanılmış ve 2002-2009 yılları arasında 8 yıllık bir süreç incelenmiş ve 52 şirket seçilmiştir. 2005 yılında Multiple R miktarı \%80.21, R ${ }^{2}$ ve Adj. R ${ }^{2}$ katsayıları sırayla \%64.33 ve \%62.88 olmuştur. 2005 yılında 31 adet IAS standardı kabul edilmiştir. 2009 yılına gelindiğinde Multiple R miktarı \%85.41, R² ve Adj. R² katsayıları sırayla \%74.94 ve \%71.84 artmıştır. Bu değerler 2009 yılında finansal raporlama kalitesinin en yüksek değerine ulaştığını göstermektedir. UFRS'nin adım adım benimsenmesinin, hisse senedi fiyatının hisse başına kazanç ve hisse senedi defter değeri ile güçlü ve artan bir ilişkiye yol açtığı sonucuna varılmıştır. Bu sonuçların Türkiye'de de uygulanabilir olması amaçlanmaktadır. Diğer taraftan yapılan araştırmada gözlem yıllarını 19 yılla çıkararak test etmek, ayrıca önceki diğger araştırmalarda yıllık bazında analizlerin bulunmaması bu araştırma için başka bir motivasyondur.

\subsection{Yöntem}

Araştırma konusu hakkında bilgilere erişebilmek için ikinci kaynak tarama yöntemiyle araştırma hipotezini test etmek içinde kesit veriler kullanılarak çok değişkenli regresyon modeli, bu modelin varsayımlarının test edilmesi ve uygun görülmesinden sonra, uygulanmıştır. Araştırmada ihtiyaca uygun veriler Borsa İstanbul'da kabul edilip işlem gören şirketlerin finansal tablolarına başvurularak elde edilmiştir. Bu nedenle seçilen şirketlerin finansal tabloları 2000 yılından 2008 yılına kadar Borsa İstanbul A. Ş. web sitesi mali tablolar arşivinden ve 2009 yılından 2018 yılına kadar Kamuyu Aydınlatma Platformu (KAP) finansal tablolar bölümünden indirilerek incelenmiştir. Dolayısıyla araştırmanın analiz dönemi 2000 yılının başından 2018 yılının sonuna kadar kapsamaktadır. Finansal tablolardan elde edilen kalemler analiz ve tahliller için Microsoft Excel 2016 paket programında bir araya getirilip hesaplanmıştır.

Araştırmanın ana kütlesi Borsa İstanbul'da kabul edilmiş ve işlem gören BIST 50'den oluşmaktadır. Araştırmanın analiz döneminde tüm ihtiyaca uygun verilerin mevcut olmaması, borsada işlemleri durdurulan şirketler olması. Bankalar, finansal yatırım ve holding şirketleri araştırmaya dahil edilmemiş olması araştırmanın açıklanan sınırlamalarıdır. Bu sebeple bazı şirketler analizden çıkarılıp nihayet 24 şirket 19 yıl boyunca (456 şirket-yıl) araştırmaya dâhil edilmiştir. Araştırma analizine dahil edilen ve analize dahil edilmeyen şirketlerin listesi ek 1'de sunulmaktadır.

\subsection{Model ve Değişkenler}

Araştırma modeli ve değişkenleri araştırma değişkenlerinin nasıl hesaplandığını açıklanmaktadır. Araştırmanın bağımlı değişkeni hisse senedi piyasa değeridir (MVPS). Bu değişken şirketin yılsonunda borsadaki kapanış fiyatı olarak açıklanmaktadır. Diğer taraftan araştırmanın bağımsız değişkenleri hisse başına kazanç (EPS) ve hisse senedi defter değeridir (BVPS). Hisse başına kazanç değişkenini hesaplamak için şirketin dönem net kar veya zararı hisse senedi sayısına 
bölünmektedir. Ayrıca hisse senedi defter değeri değişkenin hesaplamak için şirketin öz sermayesi hisse senedi sayısına bölünmektedir. Bu doğrultuda araştırma hipotezini test etmek için regresyon modeli (M1) her yıl için aşağıda açıklandığı gibi sağlanmaktadır. Bu modelde çok değişkenli regresyon (Multiple R) değişkenler arasındaki ilişkiyi, belirleme katsayısı $\left(\mathrm{R}^{2}\right)$ ve düzeltilmiş belirleme katsayısı da (Adj. $\mathrm{R}^{2}$ ) bağımsız değişkenlerin bağımlı değişkeni açıklama gücünü ölçmektedir. Dolayısıyla araştırma hipotezine göre Uluslararası Finansal Raporlama Standartlarının (UFRS) kabulü şirketler tarafından arttıkça bu modelden hesaplanan üç rakamın artması beklenilir.

$$
\operatorname{MVPS}_{\mathrm{i}, \mathrm{t}}=\alpha+\beta_{1} \mathrm{EPS}_{\mathrm{i}, \mathrm{t}}+\beta_{2} \mathrm{BVPS}_{\mathrm{i}, \mathrm{t}}+\varepsilon_{\mathrm{i}, \mathrm{t}}
$$

\subsection{Bulgular}

Ampirik olarak incelenen şirketlerin Çok Değişkenli Regresyon Analizi sonuçları Tablo 1 de sunulmaktadır. Regresyon analizinin geçerli olması için analizle ilgili verilerin Normal Dağılıma, bağımsız değişkenler arasında Çoklu Doğrusal Bağlantının olmadığına ve Eş Varyanslılık varsayımlarının test edilmesi gerekmektedir. Varsayımların test sonuçlarına göre; araştırma verilerinin dağılımı normal, hata terimleri varyansı eşit ve bağımsız değişkenler arasında çoklu doğrusal bağlantı bulunmamaktadır. Bu sonuçlara istinaden çok değişkenli regresyon analizi araştırmanın kapsadığı analiz dönemi içinde yani 2000 yılı (Multiple $\mathrm{R}=0.3032$ ) ile 2018 yılı (Multiple $\mathrm{R}=0.8740$ ) arasında olmakta ki bu artış, hisse senedi piyasa değeri ile hisse başına kazanç ve hisse senedi defter değeri arasındaki ilişkinin arttı̆̆ı göstermektedir.

Analizden ortaya çıan istatistik verilerin çok değişkenli regresyon grafiğine göre grafik 1, 2 ve 3 'te üç tepe noktada; 2007 yılında (0.5912) ile, 2012 yılında (0.8414) ile ve 2018 yılında (0.8741) ile eşit olduğu gözükmektedir. Tablo 2'deki TMS/ TFRS'lerin Yıllara göre Yürürlük Tarihlerinin Dağılımına bakıldığında, 2007 yılı için; TFRS 3, İşletme Birleşmeleri Standardı ve TFRS 7, Finansal Araçlar Standardı yürürlüğe girdiği görülmektedir. 2012 y1lı için; TFRS 10, Konsolide Finansal Tablolar Standardı ve TFRS 12, Diğer İşletmelerdeki Paylara ilişkin Açıklamalar Standartları ve TMS 27, Bireysel Finansal Tablolar Standardı ve TMS 28, İştirakler ve İş Ortaklıklarındaki Yatırımlar Standartlarının ve 2018 yılı için; TFRS 9, Finansal Araçlar Standardı ve TFRS 15, Müşteri Sözleşmelerinden Hasılat ve TFRS 16, Kiralamalar Standartlarının yürürlüğe girmeleridir. Aslında araştırmanın incelediği analiz döneminde muhasebe standartlarının ve finansal raporlama standartlarının onaylanıp yayınlanması ve uygulamaya geçmesi araştırmanın değişkenleri arasındaki ilişkinin artmasına neden olmaktadır. Diğer taraftan grafik 1, 2 ve 3’te sunulduğu gibi 2018 yılında çok değişkenli regresyonun oranı (0.8741) ile belirleme katsayısı oranı (0.7640) ile ve düzeltilmiş belirleme katsayısı oranı (0.7416) değerinde olmakta ki bu sonuçlar bu yıl için finansal raporlama kalitesinin maksimum artığını göstermektedir. Demek ki incelenen analiz döneminde finansal raporlama kalitesi 2018 yılından önceki yıllara göre en yüksek seviyesine varmıştır.

Ancak bu pozitif eğilimin devamı sürecinde bazı yıllarda, örneğin, 2002 yılı ile 2005 yıll, 2007 yılı ile 2011 yılı ve 2012 y1lı ile 2017 yılı aralıklarında şiddetli ve yetersiz miktarda düşüşler gerçekleşmekte ki bu düşüşlerin nedeni ekonomik krizlerin gerçekleşmesi sonucunda ortaya çıkmaktadır. Kasım 2001 krizi sonrası şirket bilançoları bozulmuştur. 2007 yılı yaz aylarında Mortgage kredilerinin Amerika Birleşik Devletleri’nde geri ödenmelerinde ortaya çıkan güçlüklerden ötürü finans piyasalarında dalgalanmalar başlamıştır; 2008 Kasım ayından itibaren derinlik kazanarak küresel bir finans krizine dönüşmüştür. 


\begin{tabular}{|l|c|c|c|c|c|}
\hline Tablo 1: Çok Değişkenli Regresyon Analizi Sonuçlar. \\
\hline YIL & Multiple R & $\mathbf{R}^{\mathbf{2}}$ & Adj. $\mathbf{R}^{\mathbf{2}}$ & p-value of EPS & p-value of BVPS \\
\hline $\mathbf{2 0 0 0}$ & 0.3032 & 0.0919 & 0.0055 & 0.1742 & 0.4174 \\
\hline $\mathbf{2 0 0 1}$ & 0.1553 & 0.0241 & -0.0688 & 0.4794 & 0.6892 \\
\hline $\mathbf{2 0 0 2}$ & 0.2940 & 0.0864 & -0.0006 & 0.8640 & 0.2151 \\
\hline $\mathbf{2 0 0 3}$ & 0.2277 & 0.0519 & -0.0384 & 0.6129 & 0.4095 \\
\hline $\mathbf{2 0 0 4}$ & 0.2489 & 0.0620 & -0.0274 & 0.2615 & 0.3812 \\
\hline $\mathbf{2 0 0 5}$ & 0.4713 & 0.2221 & 0.1481 & 0.0270 & 0.0321 \\
\hline $\mathbf{2 0 0 6}$ & 0.4667 & 0.2178 & 0.1433 & 0.0260 & 0.0424 \\
\hline $\mathbf{2 0 0 7}$ & 0.5912 & 0.3496 & 0.2876 & 0.0033 & 0.0053 \\
\hline $\mathbf{2 0 0 8}$ & 0.2107 & 0.0444 & -0.0466 & 0.3457 & 0.4540 \\
\hline $\mathbf{2 0 0 9}$ & 0.3915 & 0.1533 & 0.0727 & 0.0651 & 0.0938 \\
\hline $\mathbf{2 0 1 0}$ & 0.1145 & 0.0131 & -0.0809 & 0.6261 & 0.6895 \\
\hline $\mathbf{2 0 1 1}$ & 0.6470 & 0.4185 & 0.3632 & 0.0066 & 0.8018 \\
\hline $\mathbf{2 0 1 2}$ & 0.8414 & 0.7080 & 0.6802 & 0.2935 & 0.0071 \\
\hline $\mathbf{2 0 1 3}$ & 0.7370 & 0.5432 & 0.4997 & 0.1898 & 0.1505 \\
\hline $\mathbf{2 0 1 4}$ & 0.6523 & 0.4255 & 0.3708 & 0.0283 & 0.2711 \\
\hline $\mathbf{2 0 1 5}$ & 0.5773 & 0.3333 & 0.2698 & 0.0809 & 0.8406 \\
\hline $\mathbf{2 0 1 6}$ & 0.5539 & 0.3068 & 0.2408 & 0.0270 & 0.8875 \\
\hline $\mathbf{2 0 1 7}$ & 0.7388 & 0.5458 & 0.5026 & 0.0060 & 0.9881 \\
\hline $\mathbf{2 0 1 8}$ & 0.8740 & 0.7640 & 0.7416 & 0.0000 & 0.3956 \\
\hline $\mathbf{4}$ & & & & \\
\hline
\end{tabular}

Açıklamalar: Hesaplamalar, Microsoft Excel 2016 paket programında yapılmıştır.

Tablo 2: TMS/TFRS lerin Y1llara göre Yürüklük Tarihlerinin Dağılımı

\begin{tabular}{|c|c|c|c|c|c|c|}
\hline YIL & Kavramsal çerçeve & TMS & TFRS & TMS Yorum & TFRS Yorum & Toplam \\
\hline 2004 & & & & & & 0 \\
\hline 2005 & & 3 & & & 1 & 4 \\
\hline 2006 & 1 & 17 & 4 & 4 & & 26 \\
\hline 2007 & & & 2 & & 5 & 7 \\
\hline 2008 & & & & & 3 & 3 \\
\hline 2009 & & 1 & 2 & & 1 & 4 \\
\hline 2010 & & & & & 1 & 1 \\
\hline 2011 & & & & & & 0 \\
\hline 2012 & & & & & & 0 \\
\hline 2013 & & 3 & 4 & & 1 & 8 \\
\hline 2014 & & & & & 1 & 1 \\
\hline 2015 & & & & & & 0 \\
\hline 2016 & & & 1 & & & 1 \\
\hline 2017 & & & & & & 0 \\
\hline 2018 & & & 3 & & 1 & 4 \\
\hline 2019 & & 1 & & & 1 & 2 \\
\hline 2020 & 1 & & & & & 1 \\
\hline Toplam & 2 & 25 & 16 & 4 & 15 & \\
\hline
\end{tabular}




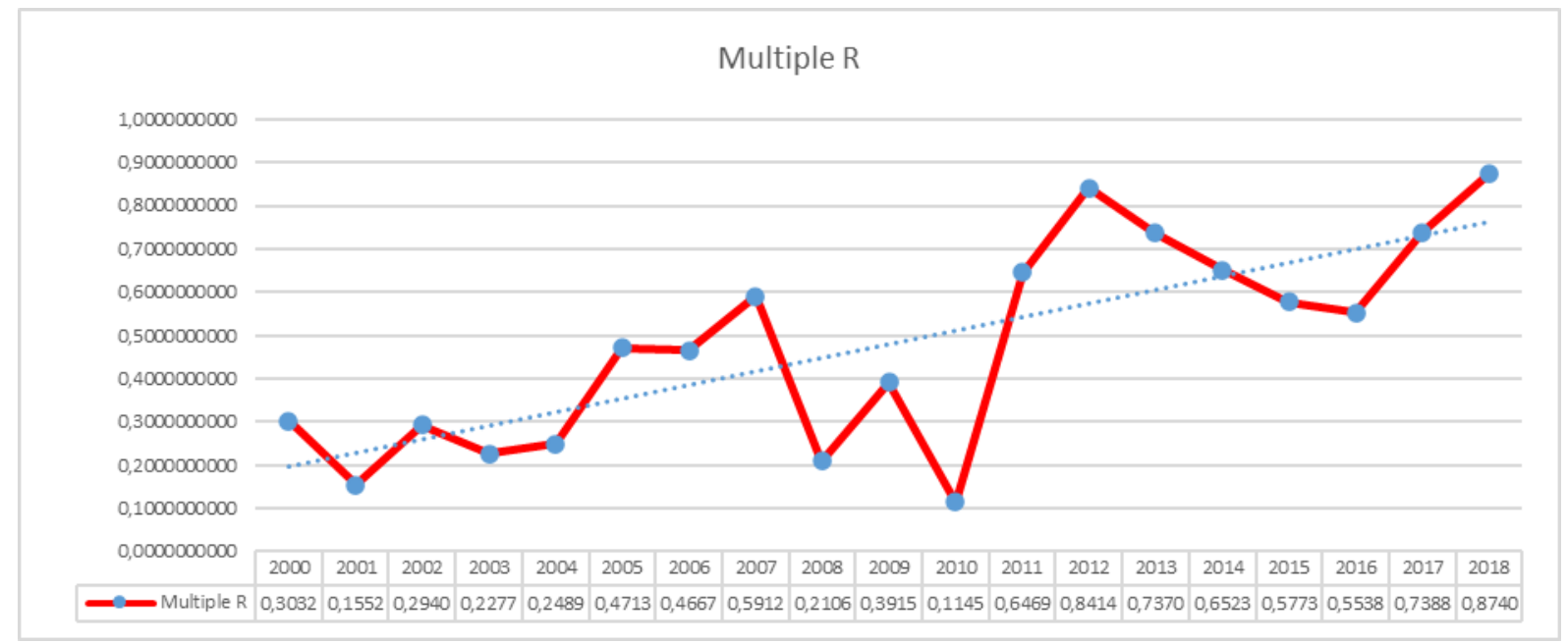

Grafik 1: Araştırma Modelinin Yıllara Ait Çok Değişkenli Regresyon Sonucunun Grafiği Açıklamalar: Hesaplamalar, Microsoft Excel 2016 paket programında yapılmıştır.

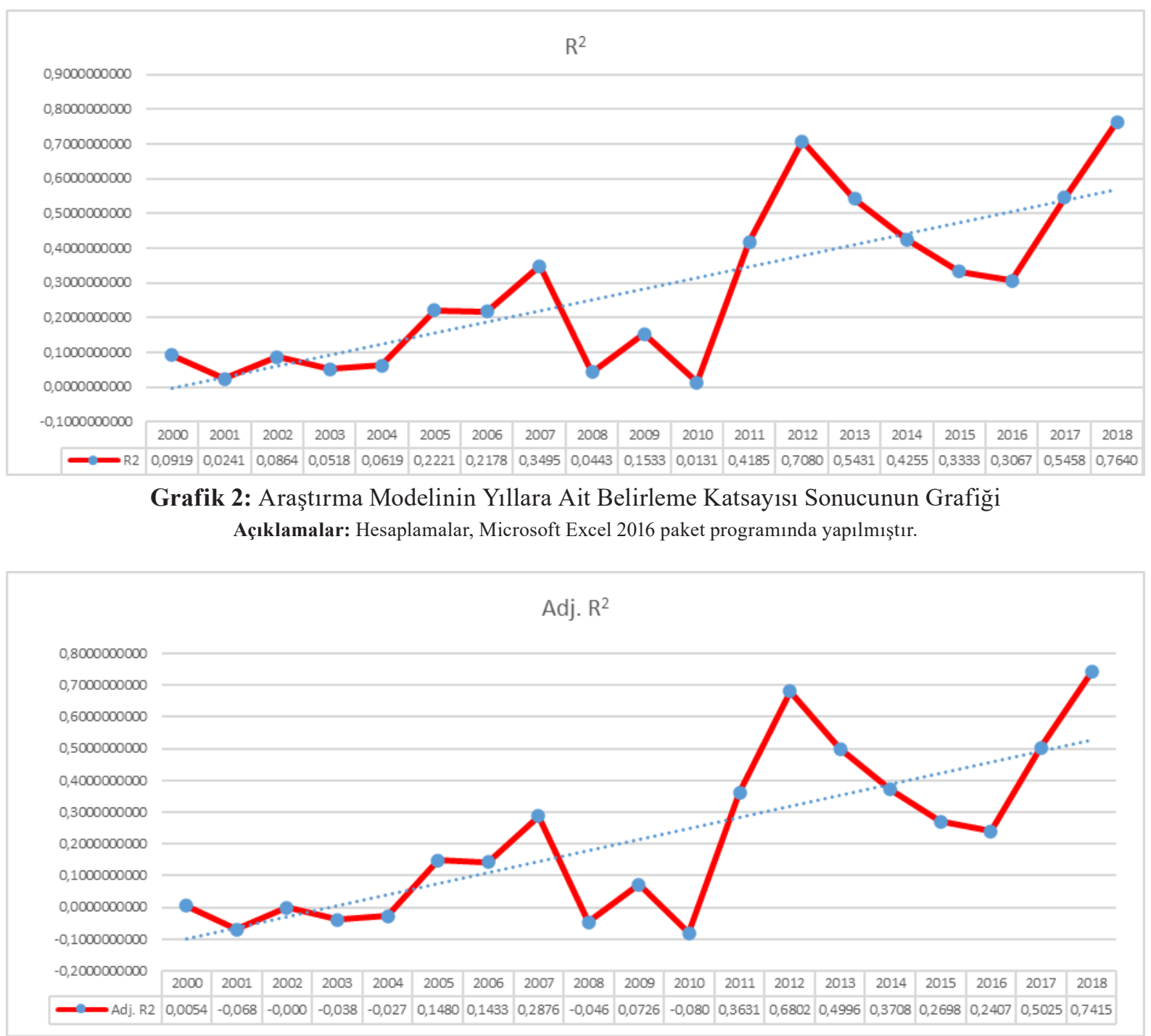

Grafik 3: Araştırma Modelinin Yıllara Ait Düzeltilmiş Belirleme Katsayısı Sonucunun Grafiği Açıklamalar: Hesaplamalar, Microsoft Excel 2016 paket programında yapılmıştır. 
Dünyada olduğu gibi Türkiye'de de 2008 yılı bir bütün olarak ekonomik krizin yoğunlaşarak devam ettiği bir yıl olmuştur. Krizden önce büyüme hızındaki düşüş küresel krizin Türkiye'ye uluslararası bankacılık sistemine dayalı kredi kanallarının çalışmaması ve sermaye girişleri ile dış talepte yaşanan azalışlar dolaşımıyla yansımasına paralel olarak 2008 yılının son çeyreğinden itibaren daralmaya dönüşmüştür. 2009 yılında, mali kuruluşlar dışında, hemen tüm sektörlerde ciddi küçülmeler yaşanmıştır. Türkiye de ekonomideki bu daralmanın çalışma yaşamı açısından ilk doğrudan etkisi işgücü üzerine olmuştur. 2008 yılında reel ekonomideki krizin, istihdam krizine dönüşmesiyle karşı karşıya kalınmıştır. Dolayısıyla 2008, 2009 ve 2010 yıllarında şirketlerin karlılıkları düşmüş hatta zarar etmişlerdir. Bu da grafik 1, 2 ve 3’teki Multiple R, $\mathrm{R}^{2}$ ve Adj. $\mathrm{R}^{2}$ değerlerinin bu tarihlerdeki keskin azalışın sebebini açıklamaktadır. Sunulan grafiklerden genel bir sonuç çıkarılırsa demek gerekir ki birincisi araştırmanın incelendiği analiz döneminde bağımsız değişkenler ile bağımlı değişken arasında artan bir ilişki bulunmakta, ikincisi ise aynı şekilde araştırmanın incelendiği analiz döneminde bağımsız değişkenler bağımlı değişkenin artan bir biçimde açıklama yeteneğine sahip olmaktadırlar.

\section{Sonuc}

$\mathrm{Bu}$ araştırmanın sonuçlarına göre Türkiye'de 2000 yılı ile 2018 yılları arasında hisse senedi piyasa değeri ile hisse başına kazanç ve hisse senedi defter değeri arasındaki ilişkinin arttığı gözükmüştür. Hisse senedi piyasa değeri ile hisse başına kazanç ve hisse senedi defter değeri arasındaki ilişki üzerine, Türkiye dışında Pakistan'da Rehana Kouser (2011), UFRS'nin benimsenmesi ve Pakistan'daki etkileri konusunda bir araştırma yapmıştır. Bu araştırmada 2002 yılı ile 2009 yılları arasında 8 yıllık bir süreç incelenmiştir. UFRS'nin benimsenmesinin, hisse senedi fiyatının hisse başına kazanç ve hisse senedi defter değeri ile güçlü ve artan bir ilişkiye yol açtı̆̆ sonucuna varılmıştır. Uluslararası finansal raporlama standartlarının adım adım onaylanıp yayınlanması ve uygulanması diğer bir ifade ile yöneticiler tarafından ülkelerde borsada işlem gören şirketlerde uygulanması finansal tabloların kalitesinin artmasına neden olmaktadır. Ayrıca finansal tabloların şeffaf ve optimum sunulması finansal tablo kalemlerinin, örneğin şirketlerin özkaynak veya dönem net kâr zarar kalemlerinin kaliteli raporlanması ile sonuçlanabilir. Dolayısıyla genellikle bu kalitenin artması hisse senedi piyasa değeri, hisse başına kazanç ve hisse senedi defter değerinin artmasına sebep olmaktadır.

Bu nedenle araştırma sonuçları, daha önce yapılmış olan diğer çalışmaları desteklemektedir. Daha sonra yapılacak olan çalışmalarda hisse senedi fiyatını etkileyecek değişken sayısı arttırılarak araştırma modeli geliştirilebilir. Ayrıca kaliteli finansal raporlamanın denetim kalitesi ile olan ilişkisi üzerine de çalışmalarda bulunulabilir. Genel olarak bakılırsa, tüm şirketlerde ve özellikle borsada işlem gören aktif şirketlerde yatırımcıların yatırımlarını şirketlere yönlendirmede ve yatırım politikalarının düzenlenmesinde, şirketlerde uluslararası finansal raporlama standartlarının gerçeğe uygun bir şekilde uygulanıp uygulanmadığını ön planda tutulduğu sonucuna varılabilir.

Hakem Değerlendirmesi: Dış bağımsız.

Çıkar Çatışması: Yazar çıkar çatışması bildirmemiştir.

Finansal Destek: Yazar bu çalışma için finansal destek almadığını beyan etmiştir.

Peer-review: Externally peer-reviewed.

Conflict of Interest: The author has no conflict of interest to declare.

Grant Support: The author declared that this study has received no financial support.

\section{Kaynaklar}

Acaravcı, K.S. (2016). Finansal oranlar ve hisse senedi getirisi ilişkisi: Borsa İstanbul üzerine bir uygulama. Mustafa Kemal Üniversitesi Sosyal Bilimler Enstitüsü Dergisi, 13(5), 263-275.

Aktaş, M. (2008). Hisse senedi seçimi ve hisse senedi seçiminde etkili olan finansal oranların belirlenmesine yönelik İMKB şirketleri üzerinde bir uygulama. İstanbul Üniversitesi, Sosyal Bilimler Enstitüsü, Doktora Tezi, İstanbul.

Alkan, B.Ş. (2019). Türkiye muhasebe ve raporlama standartlarının finansal analize etkisi. The Journal of Social Science, 5, 61-79. 
Aysan, M. (2008). Uluslararası finansal raporlama standartlarına ulusal uyum: Türkiye örneği. Erişim adresi http://journal.mufad.org. tr/attachments/article/272/4.pdf

Bartov, S., Goldberg, R. ve Kim, M. (2002). Comparative value relevance among German, US and international accounting standards: A german stock market perspective. Journal of Accounting Auditing and Finance, 20(2), 95-119.

Beisland, L.A. ve Knivsfla, K.H. (2009). Have IFRS changed how investors respond to earnings and book values? Retrieved from http:// ssrn.com/abstract $=1334533$.

Callao, S., Jarne, J. ve Lainez, J. (2007). Adoption of IFRS in Spain: Effect on the comparability and relevance of financial Reporting. Journal of International Accounting, Auditing and Taxation, 16(2), 148-178.

Clarkson, P., Hanna, J.D., Richardson, G.D. ve Thompson, R. (2011). The impact of IFRS adoption on the value relevance of book value and earnings. Journal of Contemporary Accounting and Economics, 7, 1-17.

Çukacı, Y.C. (2005). Ekonomik değer olarak bilginin muhasebe, işletmeler ve genel ekonomi açısından değerlendirilmesi. Doğu Anadolu Bölgesi Araştırmaları, 11-19.

Çürük, T. ve Tanyeri, A. (2018). Uluslararası finansal raporlama standartları 10 kapsamında konsolidasyona geçişin firmaların hisse senedi getirisi üzerindeki etkisi. Muhasebe ve Finansman Dergisi, 77, 45-54.

Gaston, S.C., Garcia, C.F., Jarne, J.I.J. ve Gadea, J.I.L. (2010). IFRS adoption in Spain and the United Kingdom: effects on accounting numbers and relevance. Advances in Accounting: Incorporating Advances in International Accounting, 26(2), 304-313.

Güvemli, O. ve Güvemli, B. (2015). Türk ticaret kanunlarının Türk muhasebe düşüncesinin gelişmesindeki etkileri. Muhasebe ve Finans Tarihi Araştırmaları Dergisi, 8, 26-50.

İbiş, C. ve Özkan S. (2006). Uluslararası finansal raporlama standartlarına (UFRS) genel bakış. Mali Çözüm Dergisi, 74 (1), $25-43$.

Kadri, M.H., Aziz, R.A. ve Mohamed, K.I. (2009). Value relevance of book value and earnings: Evidence from two different financial reporting regimes. Journal of Financial Reporting and Accounting, 7(1), 1-16.

Kandimov, S. (2020). The impact of IFRS adaption on the financial ratios of Norwegian public listed companies. University of Oulu, Oulu Business School, Master's Thesis, Finland.

Karapınar, A. (2000). Uluslararası muhasebe standartlarında şirket karı üzerine etki eden alternatif. Sosyal Bilimler Enstitüsü, Muhasebe Finansman Bilim Dall, Doktora Tezi, Ankara.

Kaya, Y. ve Utku, M. (2019). UFRS'nin Türkiye'deki gelişimi ve UFRS’ye geçişin şirketlerin finansal performansları üzerindeki etkileri. 38. Türkiye Muhasebe Eğitim Sempozyumu, 27-42.

Key, K.G. ve Kim, J.Y. (2020). IFRS and accounting quality: Additional evidence from Korea. Journal of International Accounting, Auditing and Taxation, 39, 32-45.

Kouser, R. (2011). Relationship of share price with earnings and book value of equity: paramount impact of IFRS adoption in Pakistan. Economic and Finance Review, 1(8), 84-92.

Sultanoğlu, B. (2014). UFRS'nin Borsa İstanbul'daki şirketlerin finansal tabloları üzerindeki etkisi: Finansal bilginin ihtiyaca uygunluğu ve finansal tablolar analizi. Başkent Üniversitesi, Sosyal Bilimler Enstitüsü, Muhasebe Finansman Bilim Dall, Doktora Tezi, Ankara.

Şen, İ. K. ve Terzi, S. (2013). Uluslararası finansal raporlama standartlarına geçişin özkaynak üzerine etkileri: Borsa İstanbul örneği. Muhasebe Bilim Dünyası Dergisi, 4, 1-19.

Uyar, U. (2015). Finansal raporlama standartlarının piyasa değerini açıklama üzerine etkisi. Pamukkale Üniversitesi, Sosyal Bilimler Enstitüsü, Doktora Tezi, Denizli.

Wulandari, E.R. ve Rahman, A.R. (2004). Political patronage, cross-holdings and corporate governance in Indonesia. Governance of East Asian Corporations: Post-Asian Financial Crisis, Palgrave Macmillan, New York.

Zencirkıran, S. (2015). Uluslararası muhasebe ve denetim standartlarının ulusal düzeydeki mevzuat ile ilişkisi: Türkiye örneği. Sayıştay Dergisi, 98, 61-74. 


\section{EK 1}

\begin{tabular}{|c|c|c|c|}
\hline \multicolumn{4}{|c|}{ Araştırmaya Dâhil Olan Şirketlerin Listesi } \\
\hline ID & Kod & Şirket Unvanı & Sektör \\
\hline 1 & AKENR & AKENERJİ ELEKTRİK ÜRETİM A.Ş. & ELEKTRİK GAZ VE SU \\
\hline 2 & AKSA & AKSA AKRİLIKK KİMYA SANAYİİ A.Ş. & KİMYA, PETROL KAUÇUK VE PLASTİK ÜRÜNLER \\
\hline 3 & ANACM & ANADOLU CAM SANAYIİ A.Ş. & TAŞ VE TOPRAĞA DAYALI \\
\hline 4 & AEFES & ANADOLU EFES BİRACILIK VE MALT SANAYİI A.Ş. & GIDA, İÇKİ VE TÜTÜN \\
\hline 5 & ARCLK & ARÇELIKK A.Ş. & METAL EŞYA, MAKİNE VE GEREÇ YAPIM \\
\hline 6 & ASELS & ASELSAN ELEKTRONIK SANAYİ VE TİCARET A.Ş. & TEKNOLOJI \\
\hline 7 & AYGAZ & AYGAZ A.Ş. & KİMYA, PETROL KAUÇUK VE PLASTİK ÜRÜNLER \\
\hline 8 & BRISA & BRİSA BRIDGESTONE SABANCI LASTIKK A.Ş. & KIMMYA, PETROL KAUÇUK VE PLASTİK ÜRÜNLER \\
\hline 9 & CIMSA & ÇİMSA ÇİMENTO SANAYİ VE TİCARET A.Ş. & TAŞ VE TOPRAĞA DAYALI \\
\hline 10 & EREGL & EREĞLİ DEMİR VE ÇELİK FABRİKALARI T.A.Ş. & METAL ANA SANAYİ \\
\hline 11 & FROTO & FORD OTOMOTIV SANAYİ A.Ş. & METAL EŞYA, MAKİNE VE GEREÇ YAPIM \\
\hline 12 & KORDS & KORDSA TEKNIK TEKSTIL A.Ş. & DOKUMA, GIYYIM EŞYASI VE DERİ \\
\hline 13 & LOGO & LOGO YAZILIM SANAYİ VE TİCARET A.Ş. & TEKNOLOJI \\
\hline 14 & MGROS & MIGGROS TICARET A.Ş. & TOPTAN VE PER \\
\hline 15 & NETAS & NETAŞ TELEKOMÜNİKASYON A.Ş. & TEKNOLOJI \\
\hline 16 & OTKAR & OTOKAR OTOMOTİV VE SAVUNMA SANAYİ A.Ş. & METAL EŞYA, MAKİNE VE GEREÇ YAPIM \\
\hline 17 & SODA & SODA SANAYİİ A.Ş. & KIMMYA, PETROL KAUÇUK VE PLASTİK ÜRÜNLER \\
\hline 18 & TATGD & TAT GIDA SANAYİ A.Ş. & GIDA, İÇKI VE TÜTÜN \\
\hline 19 & TOASO & TOFAŞ TÜRK OTOMOBİL FABRİKASI A.Ş. & METAL EŞYA, MAKİNE VE GEREÇ YAPIM \\
\hline 20 & TCELL & TURKCELL İLETİŞIM HİZMETLERİ A.Ş. & ULAŞTIRMA, HABERLEŞME VE DEPOLAMA \\
\hline 21 & TUPRS & TÜPRAŞ-TÜRKIYYE PETROL RAFINERİLERİ A.Ş. & KIMMYA, PETROL KAUÇUK VE PLASTİK ÜRÜNLER \\
\hline 22 & THYAO & TÜRK HAVA YOLLARI A.O. & ULAŞTIRMA, HABERLEŞME VE DEPOLAMA \\
\hline 23 & VESTL & VESTEL ELEKTRONIK SANAYİ VE TİCARET A.Ş. & METAL EŞYA, MAKİNE VE GEREÇ YAPIM \\
\hline 24 & ZOREN & ZORLU ENERJİ ELEKTRİK ÜRETIMM A.Ş. & ELEKTRIKK GAZ VE SU \\
\hline
\end{tabular}

Kaynak: Bu listedeki şirketler https://www.kap.org.tr adresinden alınmıştır.

\begin{tabular}{|c|c|c|c|}
\hline \multicolumn{4}{|c|}{ Araştırmaya Dâhil Olmayan Şirketlerin Listesi } \\
\hline ID & Kod & Şirket Unvanı & Sektör \\
\hline 1 & AKBNK & AKBANK T.A.Ş. & BANKA \\
\hline 2 & AKSEN & AKSA ENERJİ ÜRETIMM A.Ș. & ELEKTRİK GAZ VE SU \\
\hline 3 & ANELE & ANEL ELEKTRİK PROJE TAAHHÜT VE TİCARET A.Ş. & İNŞAAT VE BAYINDIRLIK \\
\hline 4 & CCOLA & COCA-COLA İÇECEK A.Ş. & GIDA, İÇKI VE TÜTÜN \\
\hline 5 & DOHOL & DOĞAN ŞİRKETLER GRUBU HOLDİNG A.Ş. & HOLDING \\
\hline 6 & DOAS & DOĞUŞ OTOMOTİV SERVISS VE TİCARET A.Ş. & TOPTAN VE PERAKENDE TİCARET \\
\hline 7 & GLYHO & GLOBAL YATIRIM HOLDİNG A.Ş. & HOLDİNG \\
\hline 8 & SAHOL & HACI ÖMER SABANCI HOLDİNG A.Ş. & HOLDING \\
\hline 9 & KCHOL & KOÇ HOLDİNG A.Ş. & HOLDİNG \\
\hline 10 & PGSUS & PEGASUS HAVA TAŞIMACILIĞI A.Ş. & ULAŞTIRMA, HABERLEŞME VE DEPOLAMA \\
\hline 11 & PETKM & PETKIMM PETROKİMYA HOLDİNG A.Ş. & HOLDİNG \\
\hline 12 & POLHO & POLİSAN HOLDİNG A.Ș. & HOLDİNG \\
\hline 13 & SKBNK & ŞEKERBANK T.A.Ş. & BANKA \\
\hline 14 & TAVHL & TAV HAVALİMANLARI HOLDİNG A.Ş. & HOLDİNG \\
\hline 15 & TKFEN & TEKFEN HOLDİNG A.Ş. & HOLDİNG \\
\hline 16 & TTKOM & TÜRK TELEKOMÜNIKASYON A.Ş. & ULAŞTIRMA, HABERLEŞME VE DEPOLAMA \\
\hline 17 & TTRAK & TÜRK TRAKTÖR VE ZİRAAT MAKİNELERİ A.Ş. & METAL EŞYA, MAKINE VE GEREÇ YAPIM \\
\hline 18 & GARAN & TÜRKIYYE GARANTİ BANKASI A.Ş. & BANKA \\
\hline 19 & HALKB & TÜRKIYYE HALK BANKASI A.Ş. & BANKA \\
\hline 20 & ISCTR & TÜRKIYE İŞ BANKASI A.Ş. & BANKA \\
\hline 21 & TSKB & TÜRKIYYE SINAİ KALKINMA BANKASI A.Ş. & BANKA \\
\hline 22 & SISE & TÜRKİYE ŞISSE VE CAM FABRİKALARI A.Ş. & HOLDİNG \\
\hline 23 & VAKBN & TÜRKIYE VAKIFLAR BANKASI T.A.O. & BANKA \\
\hline 24 & ULKER & ÜLKER BİSKÜVİ SANAYİ A.Ş. & GIDA, İÇKİ VE TÜTÜN \\
\hline 25 & VESBE & VESTEL BEYAZ EŞYA SANAYİ VE TİCARET A.Ş. & METAL EŞYA, MAKİNE VE GEREÇ YAPIM \\
\hline 26 & YKBNK & YAPI VE KREDİ BANKASI A.Ş. & BANKA \\
\hline
\end{tabular}

